\title{
Effect of boron addition on the microstructure and stress-rupture properties of directionally solidified superalloys
}

\author{
Bao-ping $W u^{1,2)}$, Lin-han $\mathrm{Li}^{1)}$, Jian-tao $\mathrm{Wu}^{2)}$, Zhen $\mathrm{Wang}^{2)}$, Yan-bin Wang ${ }^{2)}$, Xing-fu Chen ${ }^{2)}$, \\ Jian-xin Dong ${ }^{1)}$, and Jun-tao Li ${ }^{2}$ \\ 1) School of Materials Science and Engineering, University of Science and Technology Beijing, Beijing 100083, China \\ 2) Central Iron \& Steel Material Research Institute, Beijing 100081, China \\ (Received: 22 December 2013; revised: 11 May 2014; accepted: 12 May 2014)
}

\begin{abstract}
This study is focused on the effect of boron addition, in the range of $0.0007 \mathrm{wt} \%$ to $0.03 \mathrm{wt} \%$, on the microstructure and stress-rupture properties of a directionally solidified superalloy. With increasing boron content in the as-cast alloys, there is an increase in the fraction of the $\gamma^{\prime} / \gamma$ eutectic and block borides precipitate around the $\gamma^{\prime} / \gamma$ eutectic. At a high boron content of $0.03 \mathrm{wt} \%$, there is precipitation of lamellar borides. Upon heat treatment, fine block borides tend to precipitate at grain boundaries with increasing boron content. Overall, the rupture life of the directionally solidified superalloy is significantly improved with the addition of nominal content of boron. However, the rupture life decreases when the boron content exceeds $0.03 \mathrm{wt} \%$.
\end{abstract}

Keywords: superalloys; directional solidification; microstructure; boron; stress-rupture properties

\section{Introduction}

For decades now, nickel-based superalloys are being widely used in the manufacturing of gas turbine components. Directional solidification is a processing technique that results in the formation of columnar-grained casting, characterized by numerous benefits due to the absence of transverse grain boundaries.

High temperature Ni-based alloys usually contain small amounts of boron, which is considered to have important influence on their mechanical properties [1-4]. In the past decades, several studies have reported the effects of boron addition on the microstructure and properties of Ni-based alloys, such as $\mathrm{Ni}_{3} \mathrm{Al}$ [5-10]. According to these studies, boron segregation at grain boundaries increases the cohesion or decreases the grain boundary diffusivity. However, to the best of our knowledge, studies on the effect of boron on the microstructure and properties of directionally solidified alloys have been rarely reported in the literature. To this end, the aim of this study is to investigate the effect of boron ad- dition on the microstructure and properties of directionally solidified alloy.

\section{Experimental}

The nominal composition of the alloy investigated in this study (the original alloy without boron) is summarized in Table 1. The mother alloy was first prepared on a $100 \mathrm{~kg}$ vacuum induction melting (VIM) and casted into $50 \mathrm{~kg}$ alloy rods. Subsequently, pre-determined quantity of boron was added during the remelting of the alloy rods in a Bridgeman type furnace to form directionally solidified specimens of $13 \mathrm{~mm}$ in diameter and $210 \mathrm{~mm}$ in length by the method of high rate solidification at the withdrawal rate of $6 \mathrm{~mm} / \mathrm{min}$. The actual boron content in the specimens was analyzed by methyl borate distilling separation combined with inductively coupled plasma-atomic emission spectrometry. Directionally solidified slabs thus obtained with $0.0007 \mathrm{wt} \%, 0.006 \mathrm{wt} \%, 0.015 \mathrm{wt} \%$, and $0.03 \mathrm{wt} \%$ of boron were named as $\mathrm{A}, \mathrm{B}, \mathrm{C}$, and $\mathrm{D}$, respectively.

The cast specimens were subsequently heat-treated by the

Corresponding author: Bao-ping Wu $\quad$ E-mail: wbp0104@163.com

(c) University of Science and Technology Beijing and Springer-Verlag Berlin Heidelberg 2014 
following procedure: the heat treatment of $1220^{\circ} \mathrm{C} / 4 \mathrm{~h}$ and $\mathrm{AC}$, followed by the heat treatment of $980^{\circ} \mathrm{C} / 16 \mathrm{~h}$ and $\mathrm{AC}$ (AC: air cooling). Specimens of $5 \mathrm{~mm}$ in diameter and 25 $\mathrm{mm}$ in gauge length were machined longitudinally from the bars for stress-rupture testing, which was performed at $975^{\circ} \mathrm{C}$ under a stress of $196 \mathrm{MPa}$. Samples for microstructural observations were cut from the as-cast and heat-treated specimens. The samples were fabricated by the conventional method and electrochemically etched with an electrolyte consisting of $12 \mathrm{~mL} \mathrm{H}_{3} \mathrm{PO}_{4}+48 \mathrm{~mL} \mathrm{H}_{2} \mathrm{SO}_{4}+40 \mathrm{~mL} \mathrm{HNO}_{3}$. The microstructure of the cross-section and fractured surface after the stress-rupture test was observed by using an optical microscope (OM) and a scanning electron microscope (SEM) equipped with energy-dispersive X-ray spectroscopy (EDS). The change in eutectic volume fraction with elemental addition was determined quantitatively using software based on areal analysis. The average areal eutectic fraction, $A_{\mathrm{a}}$, is representative of the volume fraction, $V_{\mathrm{e}}$ :

$V_{\mathrm{e}}=A_{\mathrm{a}}=\frac{\sum A_{\mathrm{e}}}{A_{\mathrm{t}}}$,

where $\Sigma A_{\mathrm{e}}$ is the sum of the areas of the eutectic, and $A_{\mathrm{t}}$ is
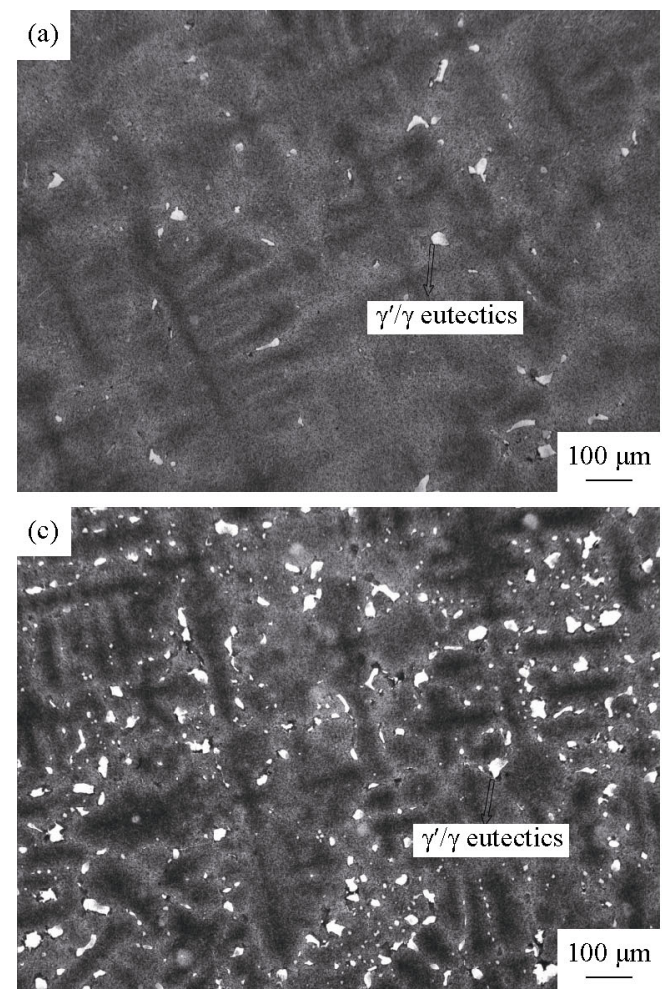

the total measurement area. In the typical analysis, 10 optical images of each sample were taken using an optical microscope at a $100 \times$ magnification in order to gain a representative sample area and a statistically significant average volume fraction.

Table 1. Nominal composition of the alloy $w t \%$

\begin{tabular}{cccccccccc}
\hline $\mathrm{C}$ & $\mathrm{Cr}$ & $\mathrm{Co}$ & $\mathrm{W}$ & $\mathrm{Mo}$ & $\mathrm{Al}$ & $\mathrm{Ti}$ & $\mathrm{V}$ & $\mathrm{Nb}$ & $\mathrm{Ni}$ \\
\hline 0.16 & 9.33 & 13.92 & 1.41 & 3.25 & 5.42 & 4.57 & 0.84 & 0.83 & Bal. \\
\hline
\end{tabular}

\section{Results}

\subsection{Effect of boron addition on the microstructure}

The microstructure of directionally solidified castings with different boron contents is shown in Fig. 1. As is seen, the as-cast structure is dendritic with a dendrite segregation pattern. The $\gamma^{\prime} / \gamma$ eutectic, which solidified finally during the solidification process, is located preferentially in the interdendritic regions. Fig. 2 plots the variation of eutectic fraction in the as-cast alloy as a function of boron content. As is seen, the eutectic fraction increases with increasing boron content.
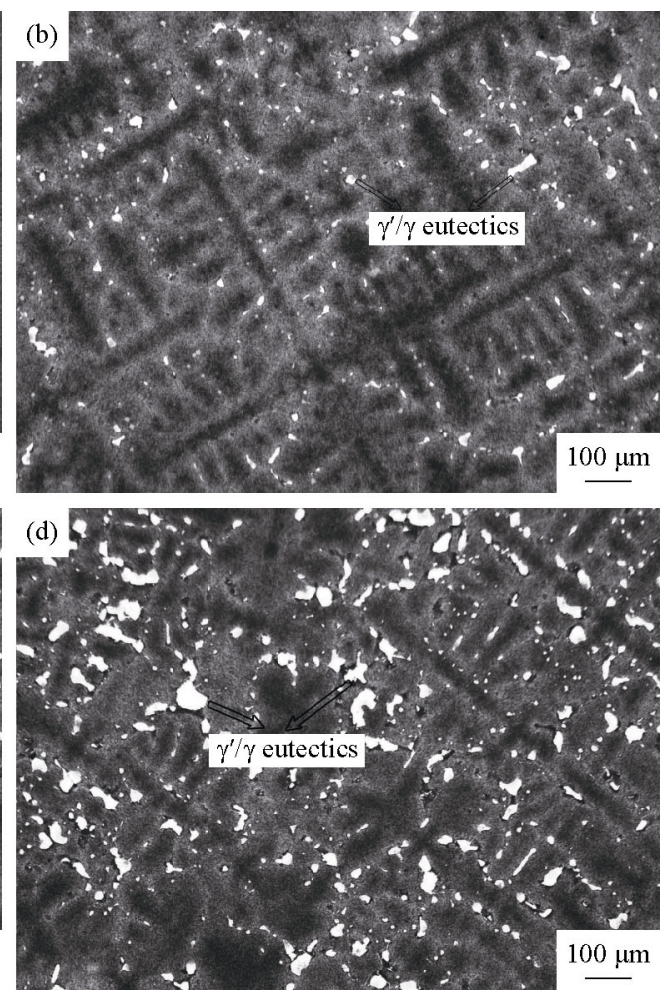

Fig. 1. Increase of eutectic fraction in the as-cast alloys with increasing boron content: (a) alloy A; (b) alloy B; (c) alloy C; (d) alloy D.

After heat treatment, the segregation of alloy elements is dramatically reduced by diffusion at high solution temperature. The $\gamma^{\prime} / \gamma$ eutectic is dissolved in the $\gamma$ matrix, and the den- dritic structure is partly removed. Four SEM images of the heat-treated alloys shown in Fig. 3 reveal the $\gamma^{\prime} / \gamma$ eutectic still presents due to high eutectic fraction after heat treatment. 


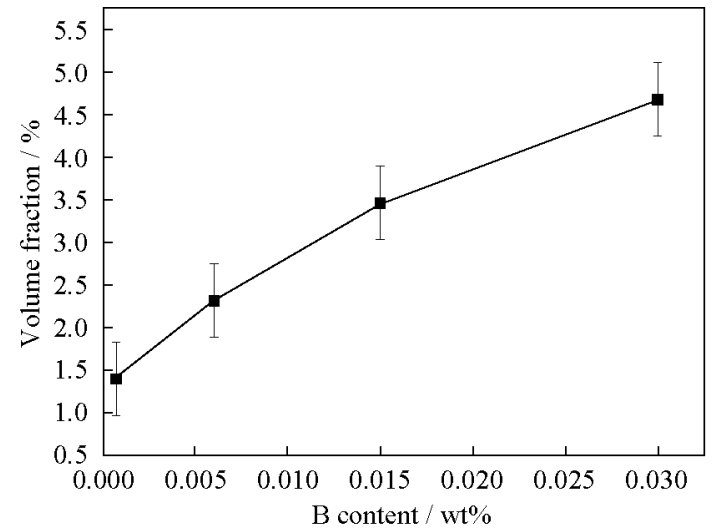

Fig. 2. Eutectic fraction in alloys with different B contents.
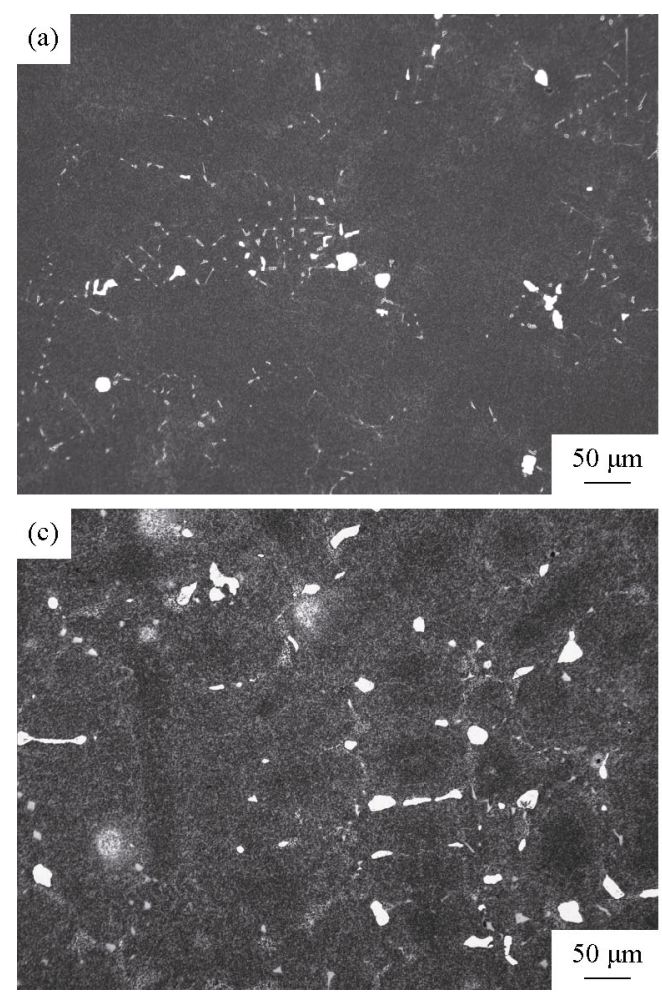

\subsection{Formation of borides}

The addition of boron in the experimental alloys (alloys A-D) results in the formation of a small amount of borides. As can be seen from the SEM image shown in Fig. 4(a), borides are not observed in alloy A due to the very small concentration of boron in the alloy. With the increasing of boron content in the as-cast alloys (Figs. 4(b) and 4(c)), more block boride precipitates appear around the $\gamma^{\prime} / \gamma$ eutectics. With further increase in boron content to $0.03 \mathrm{wt} \%$ (Fig. 4(d)), lamellar borides are observed at the solidification front of the $\gamma^{\prime} / \gamma$ eutectics. EDS analysis (Fig. 4(e)) suggests that the boride phase is mainly enriched with $\mathrm{Cr}$ and Mo.
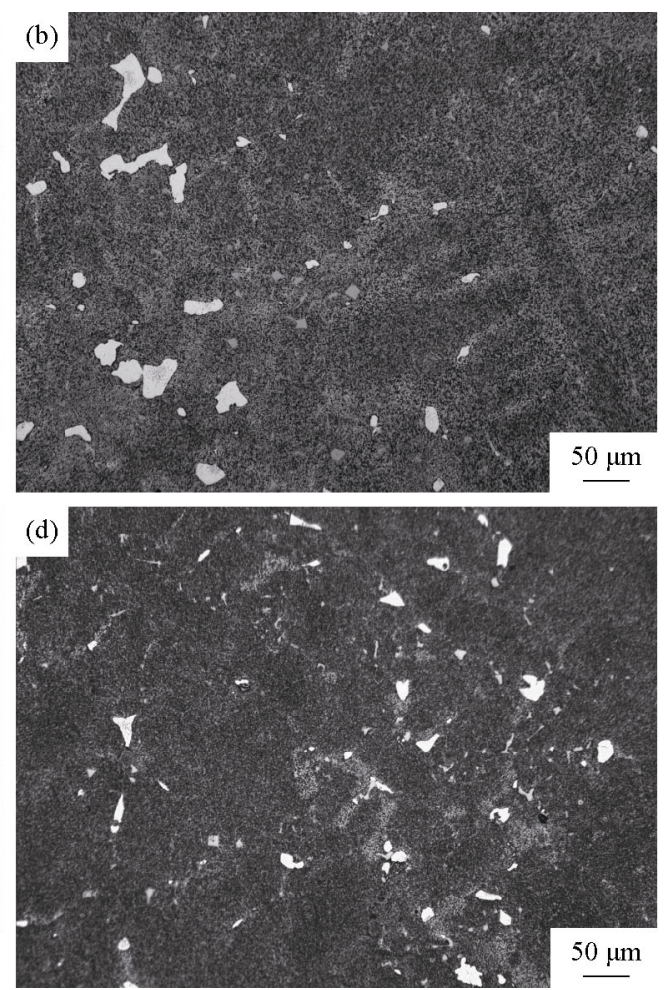

Fig. 3. Eutectic fraction in alloys after the heat treatment: (a) alloy A; (b) alloy B; (c) alloy C; (d) alloy D.

Upon heat treatment, the $\gamma^{\prime} / \gamma$ eutectics dissolve in the $\gamma$ matrix, together with the reprecipitation of borides at grain boundaries and around carbides (Fig. 5). The precipitation of borides is still not observed in alloy A, as shown in Fig. 5(a). On the other hand, in the case of alloys B and C (Figs. 5(b) and 5(c)), block borides form at grain boundaries and around carbides. With further increase in boron content, lamellar borides reprecipitate at grain boundaries, as seen in Figs. 5(c) and 5(d).

\subsection{Stress-rupture test}

The stress-rupture test was conducted at $975^{\circ} \mathrm{C}$ under a stress of $196 \mathrm{MPa}$. The corresponding results are plotted in Fig. 6. As is seen, the stress-rupture life and elongation increase with increasing boron content and reach the maximum value for the boron content of $0.015 \mathrm{wt} \%$. With further increase in boron content to $0.03 \mathrm{wt} \%$, there is a decrease in rupture life and elongation.

\subsection{Fractographs}

The microstructure of the longitudinal section of the alloys after the rupture test is shown in Fig. 7. The boron addition has dramatic effect on the fracture behavior. Alloy A with $0.0007 \mathrm{wt} \%$ boron exhibits mainly intergranular frac- 
ture (Figs. 7(a)-7(b)). With increasing boron content to $0.015 \mathrm{wt} \%$ (alloy $\mathrm{C}$ ), the fractured surface exhibits the feature of transgranular fracture, as shown in Figs. 7(c)-7(d).
With further increase in boron content to $0.03 \mathrm{wt} \%$, the fractured surface exhibits mixed intergranular and transgranular features, as shown in (Figs. 7(e)-7(f)).
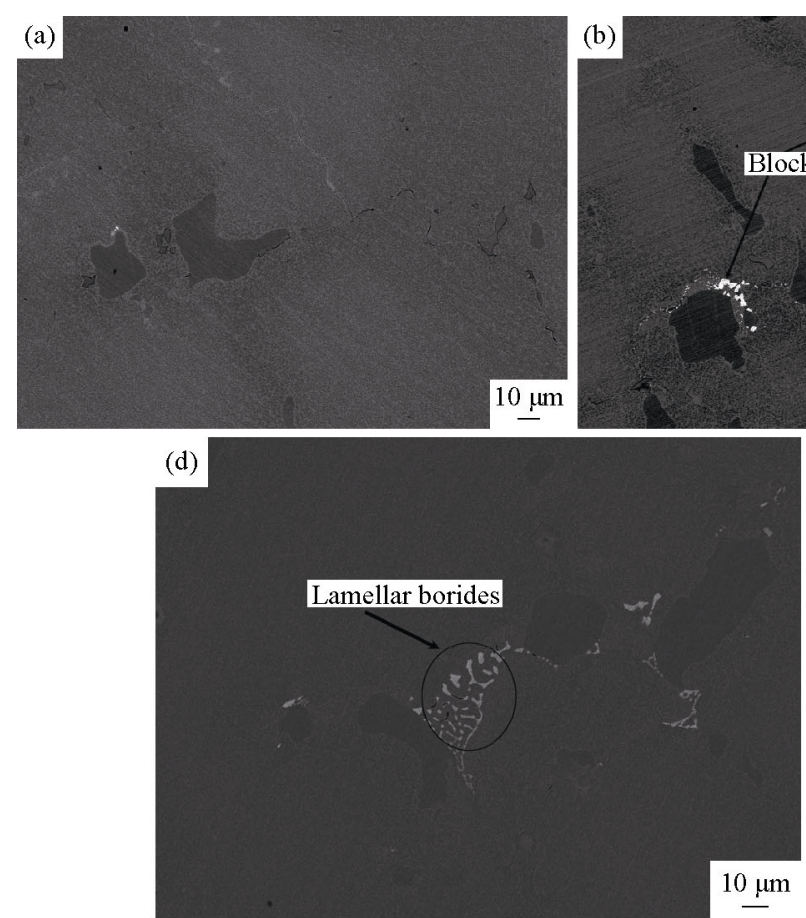
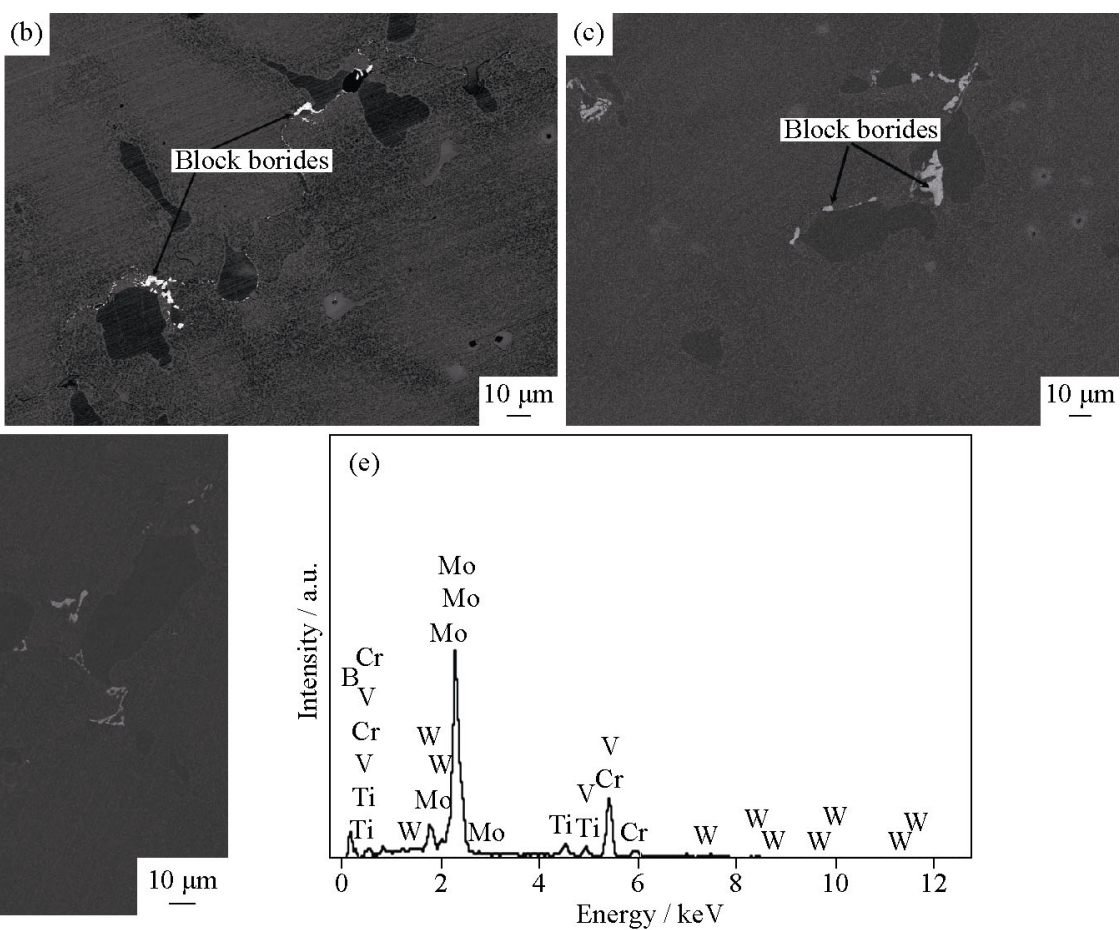

Fig. 4. Backscattered SEM images of the as-cast samples and EDS analysis: (a) alloy A; (b) alloy B; (c) alloy C; (d) alloy D; (e) EDS analysis of borides.
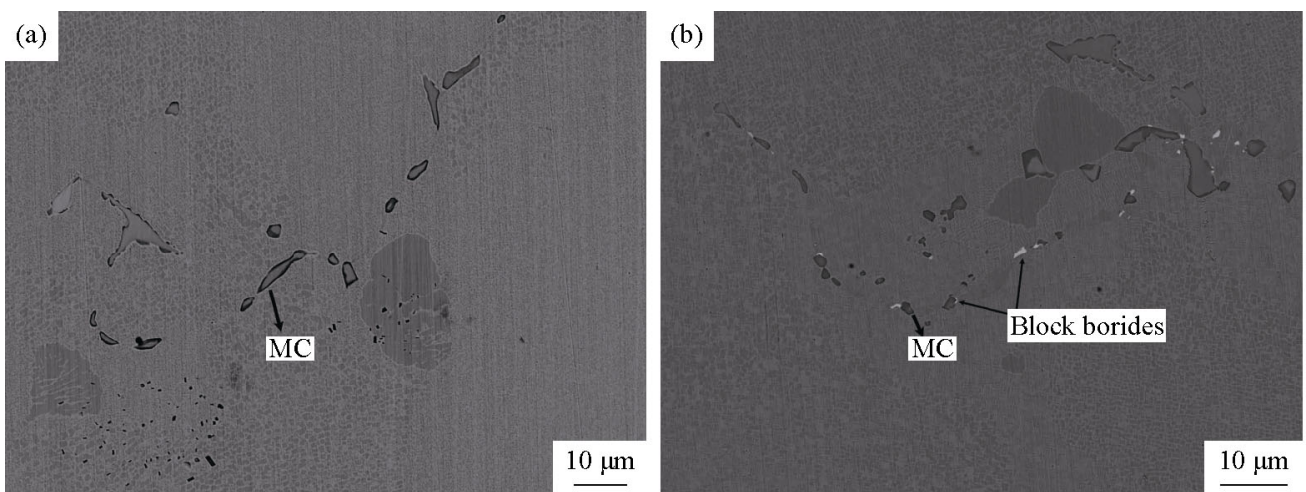

(c)

(d)
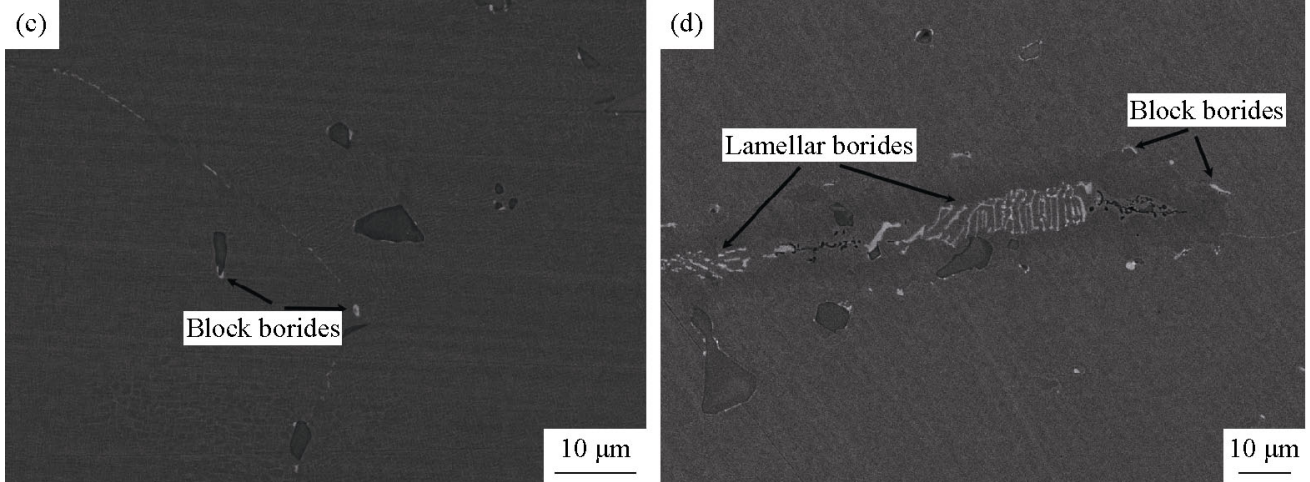

Fig. 5. Backscattered SEM images of heat-treated samples: (a) alloy A; (b) alloy B; (c) alloy C; (d) alloy D. 


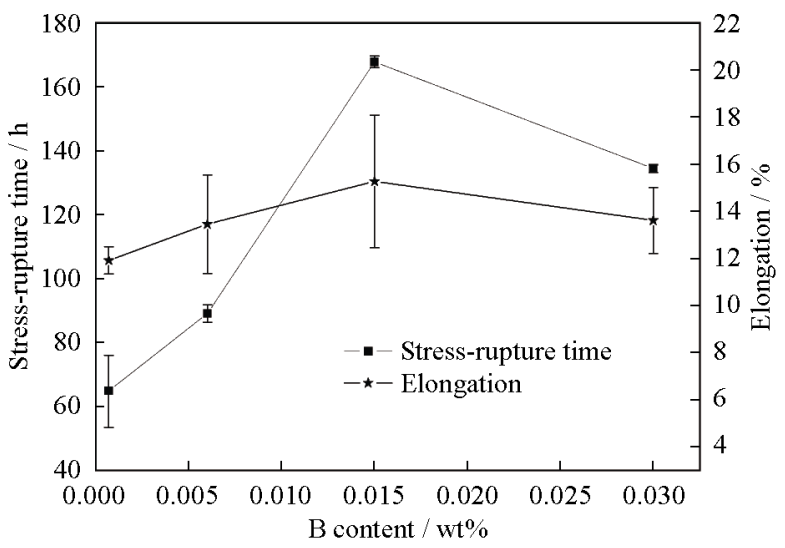

Fig. 6. Stress-rupture life and elongation of the alloys with different boron contents at $975^{\circ} \mathrm{C}$ under a stress of $196 \mathrm{MPa}$.
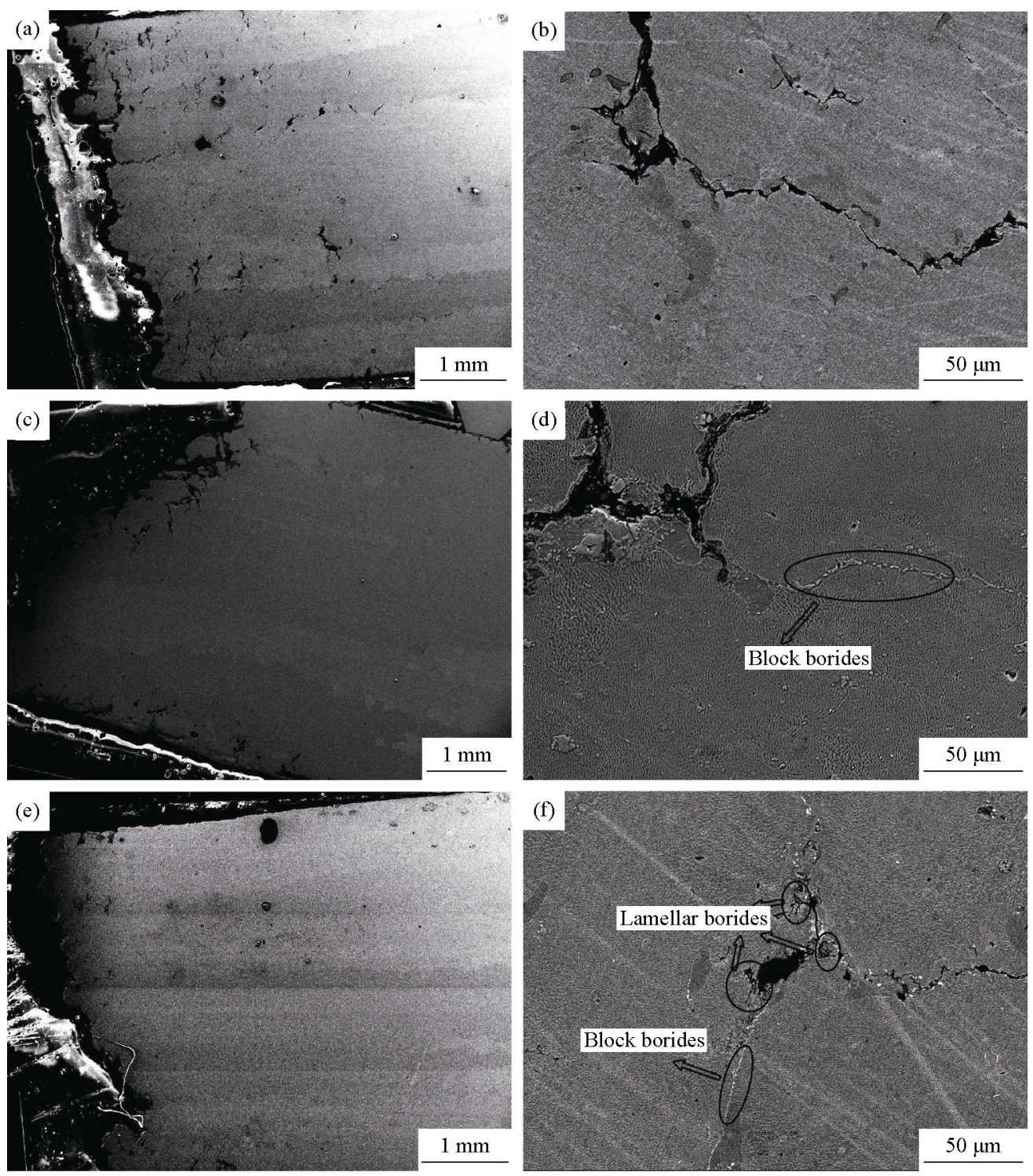

Fig. 7. Fractured surfaces of specimens after stress-rupture test: (a,b) alloy A; (c,d) alloy C; (e,f) alloy D. 
Boron is an interstitial microalloying element, which is characterized by low solubility in solid solution. Thus, when the boron content exceeds its solubility limit in the as-cast alloys, block borides precipitate in the interdendritic regions (Figs. 4(b) and 4(c)). Further increase in boron content results in the formation of lamellar borides, as shown in Fig. 4(d). Borides form around $\gamma^{\prime} / \gamma$ eutectics and are enriched with $\mathrm{Cr}$ and Mo (Fig. 4). Similar results have been reported in many alloys $[3,12-13]$. Since $\mathrm{Cr}$ and Mo have low concentrations in $\gamma^{\prime}$ phase, the formation of $\gamma^{\prime} / \gamma$ eutectics leads to increases in $\mathrm{Cr}$ and Mo contents in the remaining liquid in front of the solidifying $\gamma^{\prime} / \gamma$ eutectics. Consequently, $\mathrm{Cr}$ and Mo elements enrich around the regions where the boride phase is formed.

Ideally, the grain boundary of directional castings, all oriented in the $<100>$ crystallographic direction, should be parallel to the direction of stress. However, the grain boundary is rather winding, and is not completely parallel to the direction of stress (Figs. 7(b), 7(d), and 7(f)). Therefore, the stress tends to concentrate at the winding grain boundary, which is weak at elevated temperatures. The effect of boron atoms in grain boundaries has been proved by previous report [14-19]. According to those studies, boron segregation at grain boundaries reduces the grain boundary energy and significantly increases the grain boundary cohesion. After heat treatment, the observed increase in rupture life of alloys with increasing boron content, as shown in Fig. 6, indicates that boron plays an important role in the strengthening of grain boundaries during the rupture test. The stress-rupture fracture mode transforms from intergranular to transgranular with increasing boron content, which is also indicative of the strengthening of grain boundaries. Upon heat treatment, fine block borides are formed at grain boundaries, and this is an ideal morphology for inhibiting grain boundary sliding and for resisting grain boundary cracking. As a result, the rupture life of the alloys increases considerably with increasing boron content. However, with further increase in boron content to $0.03 \mathrm{wt} \%$ (alloy D), lamellar borides are formed at grain boundaries. The rupture life of alloy D decreases and its fracture mode transforms from transgranular to mixed transgranular and intergranular fracture (Fig. 7). This indicates that the addition of excess boron will lead to the formation of lamellar borides at grain boundaries, which in turn will make the interfaces brittle and decrease the rupture life.

\section{Conclusions}

In summary, this paper investigates the effect of boron addition on the microstructure and properties of directionally solidified alloys. The following conclusions can be obtained based on the systematic analysis of the as-cast and heat-treated alloys:

(1) The eutectic fraction in the as-cast alloys increases with increasing boron content. After heat treatment, the $\gamma^{\prime} / \gamma$ eutectic is partly dissolved in the $\gamma$ matrix.

(2) In the as-cast alloys, borides precipitate around the $\gamma^{\prime} / \gamma$ eutectic with increasing boron content. Upon heat treatment, fine block borides precipitate at grain boundaries with increasing boron content. At a high boron content of the order of $0.03 \mathrm{wt} \%$, lamellar borides tend to form at grain boundaries.

(3) The rupture life of the alloys increases with increasing boron content, indicating that the grain boundary is strengthened by the addition of boron. However, the addition of excess boron will lead to the formation of lamellar borides at grain boundaries, which in turn will decrease the rupture life.

\section{References}

[1] R. Sellamuthu and A.F. Giamei, Measurement of segregation and distribution coefficients in MAR-M200 and hafnium-modified MAR-M200 superalloys, Metall. Trans. A, 17(1986), No. 3, p. 419.

[2] V.A. Wills and D.G. McCartney, A comparative study of solidification features in nickel-base superalloys: microstructural evolution and microsegregation, Mater. Sci. Eng. A, 145(1991), No. 2, p. 223.

[3] A.V. Shulga, Boron and carbon behavior in the cast Ni-base superalloy EP962, J. Alloys Compd., 436(2007), No. 1-2, p. 155.

[4] E.R. Cutler, A.J. Wasson, and G.E. Fuchs, Effect of minor alloying additions on the carbide morphology in a single crystal Ni-base superalloy, Scripta Mater., 58(2008), No. 2, p. 146.

[5] S.C. Huang, A.I. Taub, and K.M. Chang, Boron extended solubility and strengthening potency in rapidly solidified $\mathrm{Ni}_{3} \mathrm{Al}$, Acta Metall., 32(1984), No. 10, p. 1703.

[6] I. Baker, B. Huang, and E.M. Schulson, The effect of boron on the lattice properties of $\mathrm{Ni}_{3} \mathrm{Al}$, Acta Metall., 36(1998), No. 3, p. 493.

[7] C.T. Liu, C.L. White, and J.A. Horton, Effect of boron on grain-boundaries in $\mathrm{Ni}_{3} \mathrm{Al}$, Acta Metall., 33(1985), No. 2, p. 213.

[8] J.T. Guo, H. Li, C. Sun, S.H. Wang, D.G. Ren, L.Y. Xiong, and J. Jiang, Behaviour of boron in poly- and monocrystalline $\mathrm{Ni}_{3} \mathrm{Al}$ and its effect strength at room and high temperature, Mater. Sci. Eng. A, 152(1992), No. 1-2, p. 120.

[9] P.S. Khadkikar, K. Vedula, and B.S. Shabel, The role of boron in ductilizing $\mathrm{Ni}_{3} \mathrm{Al}$, Metall. Trans. A, 18(1987), No. 3, p. 425. 
[10] D.A. Muller, S. Subramanian, P.E. Batson, J. Silcox, and S.L. Sass, Structure, chemistry and bonding at grain boundaries in $\mathrm{Ni}_{3} \mathrm{Al}$ : I. The role of boron in ductilizing grain boundaries, Acta. Mater., 44(1996), No. 4, p. 1637.

[11] Q. Hu, L. Liu, X.B. Zhao, S.F. Gao, J. Zhang, and H.Z. Fu, Effect of carbon and boron additions on segregation behavior of directionally solidified nickel-base superalloys with rhenium, Trans. Nonferrous Met. Soc. China, 23(2013), No. 11, p. 3257.

[12] B.C. Yan, J. Zhang, and L.H. Lou, Effect of boron additions on the microstructure and transverse properties of a directionally solidified superalloy, Mater. Sci. Eng. A, 474(2008), No. 1-2, p. 39.

[13] E. Cadel, D. Lemarchand, S. Chambrel, and D. Blavette, Atom probe tomography investigation of the microstructure of superalloys N18, Acta Mater., 50(2002), No. 5, p. 957.

[14] D. Mukherji, J. Rösler, M. Krüger, M. Heilmaier, M.C. Bölitz, R. Völkl, U. Glatzel, and L. Szentmiklósi, The effects of boron addition on the microstructure and mechanical properties of Co-Re-based high-temperature alloys, Scripta Mater.,
66(2012), No. 1, p. 60.

[15] X. Huang, M.C. Chaturvedi, N.L. Richards, and J. Jackman, The effect of grain boundary segregation of boron in cast alloy 718 on HAZ microfissuring: a SIMS analysis, Acta Mater., 45(1997), No. 8, p. 3095.

[16] W. Chen, M.C. Chaturvedi, N.L. Richards, and G. McMahon, Grain boundary segregation of boron in INCONEL 718, Metall. Mater. Trans. A, 29(1998), No. 7, p. 1947.

[17] D. Blavette, P. Duval, L. Letellier, and M. Guttmann, Atomic-scale APFIM and TEM investigation of grain boundary microchemistry in astroloy nickel base superalloys, Acta Mater., 44(1996), No. 12, p. 4995.

[18] L. Letellier, A. Bostel, and D. Blavette, Direct observation of boron segregation at grain boundaries in astrology by $3 \mathrm{D}$ atomic tomography, Scripta Metall. Mater., 30(1994), No. 12, p. 1503.

[19] J.M. Walsh and B.H. Rear, Direct evidence for boron segregation to grain boundaries in a nickel-base alloy by secondary ion mass spectrometry, Metall. Trans. A, 6(1975), No. 1, p. 226. 